Article

\title{
When Italians Follow the Rules against COVID Infection: A Psychological Profile for Compliance
}

\author{
Mirko Duradoni ${ }^{1, *(D)}$, Maria Fiorenza ${ }^{2}$ and Andrea Guazzini ${ }^{2,3}$ (D) \\ 1 Department of Industrial Engineering, University of Florence, 50139 Florence, Italy \\ 2 Department of Education, Literatures, Intercultural Studies, Languages and Psychology, \\ University of Florence, 50135 Florence, Italy; m.martina.fiorenza@gmail.com (M.F.); \\ andrea.guazzini@unifi.it (A.G.) \\ 3 Centre for the Study of Complex Dynamics, University of Florence, 50135 Florence, Italy \\ * Correspondence: mirko.duradoni@unifi.it
}

Citation: Duradoni, M.; Fiorenza, M.; Guazzini, A. When Italians Follow the Rules against COVID Infection: A Psychological Profile for Compliance. COVID 2021, 1, 246-262. https:// doi.org/10.3390/covid1010020

Academic Editor: Andrea Fiorillo

Received: 14 May 2021

Accepted: 16 August 2021

Published: 18 August 2021

Publisher's Note: MDPI stays neutral with regard to jurisdictional claims in published maps and institutional affiliations.

Copyright: (c) 2021 by the authors. Licensee MDPI, Basel, Switzerland. This article is an open access article distributed under the terms and conditions of the Creative Commons Attribution (CC BY) license (https:// creativecommons.org/licenses/by/ $4.0 /)$.

\begin{abstract}
The 2019 coronavirus (COVID-19) outbreak has drastically changed people's lifestyles and forced them to adopt new behaviors. To assess Italians' reported compliance to the behavioral provisions issued by the Italian Ministry of Health against the COVID-19 pandemic and identify the socio-demographic and psychological profile of a person who is more likely to comply with them, we conducted a quantitative study with 1556 participants. Notably, in Italy, after a month of lockdown, the reported compliance with anti-COVID prescriptions was high overall. Moreover, personality traits, risk perception, well-being levels, and emotional activations appeared to play a role in promoting or hindering people's reported compliance. These findings emphasize the importance of being aware of the reported compliance's antecedents for defining advanced pro-compliance policies and messages and thus better manage each stage of the COVID-19 pandemic in Italy and, plausibly, in other countries.
\end{abstract}

Keywords: compliance; COVID-19; anti-COVID prescriptions; anti-contagion rules; mental health

\section{Introduction}

The COVID-19 outbreak, starting in December 2019, was officially classified by the $\mathrm{WHO}$ as a global pandemic on 11 March 2020. From the early stages, this emergency forced the governments of many states in the world to produce guidelines to combat the transmission of the virus [1]. A series of studies conducted during the lockdown period emphasized the negative impact of these anti-contagion rules (e.g., quarantine, social distancing, global surveillance) on people's mental health [2]. For example, Ahmed and colleagues reported a higher rate of anxiety, depression, alcohol use disorder, and more psychological distress (e.g., lower mental well-being) [3,4]. Moreover, Xiang and colleagues reported that home quarantine and isolation may induce feelings of loneliness and anger [5]. Similar results regarding short-term effects (i.e., anxiety, depression, anger, and other associated psychological problems) were identified in medical and related personnel and in confirmed and suspected patients [5,6]. The literature reported that in pandemic scenarios, the effectiveness of anti-contagion prescriptions depended on people's compliance [7], which is affected by many factors [8,9]. Indeed, several studies found that sociodemographic (e.g., gender differences) and psychological variables (e.g., personality traits, risk perception) were able to predict people's compliance with anticontagion rules [8]. For instance, women were more likely to endorse precautionary measures (e.g., maintain personal hygiene, avoid physical contact) than men during a respiratory pandemic $[10,11]$. Personality traits, in general, facilitate the adoption of health behaviors [12]. Although little is known about personality in the context of infectious disease [13], a lot of studies highlighted that conscientiousness and agreeableness appear likely to predict health and risk behaviors [14]. In a respiratory pandemic situation, health 
behavior is also related to risk perception [15], which promotes protective behaviors (e.g., handwashing; [16]). As evidenced by Wise and colleagues, in the COVID-19 pandemic, higher perceived personal risk increased engagement with anti-COVID rules [17].

A series of studies around the world also contributed to the understanding of how people respond to the COVID-19 mitigation measures by identifying some major associated variables. Some research highlighted the role of gender [18,19], indicating that females (versus males) had generally higher compliance with COVID-19 mitigation measures. Other analyses found an association between compliance and age [18], suggesting that older people may have more capacity to comply. Moreover, conscientiousness, openness, and neuroticism personality traits were related to anti-COVID behavioral norms adherence $[20,21]$. Other psychological factors that seemed to be related to compliance were social connectedness [22], readiness to change [23], self-efficacy [18,19,24], negative emotions experienced by people [19], risk perception, and the related fear of contracting a SARS-CoV-2 infection [17-19,25-27]. Finally, people's wellbeing also appeared to be related to compliance during the COVID-19 pandemic. More specifically, lower life satisfaction, happiness, and higher negative mood were associated with lower compliance [28].

So far, no study had accounted for all these psychological factors affecting compliance at the same time. Thus, in our study, we aimed to fill this gap by comparing the effect sizes of both psychological and socio-demographic variables to understand the strength of the relationship that each of them has with self-reported compliance in our specific case. In the end, the study provides an overview of the effects most associated with reported compliance by organizing them from the strongest to the weakest effect.

\section{Material and Methods}

\subsection{Participants and Design}

The sample of the study was composed of 1556 participants (253 male and 1303 female), with an average age of 27.88 years (standard deviation $=10.33$ years) through a voluntary census on the web.

\subsection{Materials}

To identify which psychological variables represent the antecedents of compliance to the provisions issued by the Italian Ministry of Health against the COVID-19 pandemic, we administered an online survey investigating the participants' socio-demographic characteristics, personality traits, self-efficacy, well-being, and social connectedness, which can be threatened due to quarantine. We relied on all those socio-demographic and psychological factors that appeared as the most relevant in the literature for modeling compliance in a specific situation, such as respiratory pandemic scenarios [8,29].

The survey was composed of the following tools:

1. Socio-demographic form: This was composed of questions about gender, age, education, marital status, occupational status, housing situation, knowing someone that was infected with SARS-CoV-2, and owning a pet animal.

2. Reported compliance form: This was created ad hoc based on ten behavioral provisions issued by the Italian Ministry of Health against the COVID-19 pandemic. It included issues related to the degree of information (anti-COVID knowledge self-perception) and the motivation to follow the rules. A 5-point Likert scale ranging from rarely or not at all (1) to always (5) was used. The behavioral norms that Italians were asked to comply with were: the practice of washing your hands often with an alcohol-based gel; avoid close contact with people suffering from acute respiratory infections, do not touch the eyes, nose, and mouth with the hands; cover the mouth and nose with a tissue, hands, or with arms whenever you cough or sneeze; avoid taking antibiotics or antiviral medication, unless prescribed by a physician; clean surfaces with chlorine- or alcohol-based disinfectants; use a face mask if you go out or if you are caring for people who are ill; in case of doubts do not go to an emergency room, hospital, or clinic but contact your doctor. The overall reported compliance was computed by summing the 
score of each question regarding anti-COVID prescriptions. The variable resulted in a non-normal distribution (i.e., a kurtosis value higher than +1 ).

3. Ten-Item Personality Inventory (I-TIPI) [30]: We used the validated Italian version, which was developed from the original scale of [31]. The scale is composed of 10 items, which evaluates five dimensions: extraversion (e.g., extraverted, enthusiastic), agreeableness (e.g., sympathetic, warm), conscientiousness (e.g., dependable, self-disciplined), emotional stability (e.g., calm, emotionally stable), and openness to experience (e.g., open to new experiences, complex). Subjects rate the extent to which certain personality traits apply to them on a scale ranging from disagree strongly (1) to agree strongly (5) on a 5-point Likert scale.

4. The Self-Efficacy Scale [32]: This scale used in the Italian version [33] investigates the self-efficacy perception of the participants. The scale consists of ten items graded on a 4-point Likert scale from "Not at all true" (1) to "Exactly true" (4). The Cronbach's alpha ranged from 0.76 to 0.90 . The scale is unidimensional. Examples of items include: "I am confident that I could deal efficiently with unexpected events" and "I can usually handle whatever comes my way."

5. Cognitive Factors of the Risk Perception Regarding COVID-19 [34]: Cognitive factors of risk perception were assessed using five items $(\alpha=0.79)$ concerning the perceived severity of COVID-19. One of these items concerns the likelihood of infection and another one concerns perceived coping efficacy. Responses were provided using a 5point Likert-type scale ( $0=$ not at all, $5=$ extremely). The items were adapted by replacing "Swine Flu" with "COVID-19." Examples of items are: "Do you think that COVID-19 is a serious condition?" and "Do you think you are at risk of catching COVID-19?".

6. Risk Perception [35]: In the literature review conducted by Wilson and colleagues in 2019, they identified a multidimensional measure of risk perception that included affect, probability, and consequences dimensions. This scale was translated into Italian and adapted to the pandemic scenario. In particular, item 7 , which asked about the likelihood that an event $X$ will occur where they live, was changed to ask whether the likelihood that the number of people infected by COVID-19 will increase where they live since the pandemic was already in place. Item 8 was removed since it was unsuitable for our purposes (i.e., "How often do X occur where you live"). Perceived risk was elicited using nine items graded on a 5-point Likert-type scale ( $0=$ not at all, $5=$ extremely). In the study of Ding and colleagues, the internal reliability was $\alpha=0.64$ [36].

7. Change Questionnaire (CQ) [37]: The CQ is a recently developed 12-item measure. The respondent identifies what they are considering changing (e.g., "to worry less"), and items are completed with reference to that change. Two items each represent desire, ability, reasons, need, commitment to change, and taking steps to change, and are rated on a 0 (definitely not) to 10 (definitely) scale according to the degree that each statement describes their motivation (e.g., "I want to worry less" and "I could worry less"). The total scores range from 0 to 120 , with higher scores indicating higher levels of change talk or motivation. The CQ has good internal consistency and test-retest reliability.

8. Social Connectedness Scale-Revised (SCS-R) [38]: The Italian validation developed from the original scale of [39] investigates the participants' experiences of closeness in interpersonal contexts, as well as problems establishing and maintaining a sense of closeness. Example items include: "I don't feel I participate with anyone or any group" and "I am in tune with the world." The scale is composed of twenty items on a 6 -point Likert scale $(1=$ strongly disagree to $6=$ strongly agree). Authors consider a mean item score equal to or greater than 3.5 (slightly agree to strongly agree) as indicating a greater tendency to feel socially connected. The SCS-R had good psychometric properties, with an average inter-item correlation of 0.66 and alpha $=0.92$ in our sample.

9. Warwick-Edinburgh Mental Well-Being Scale (WEMWBS) [40]: This scale was developed by [41] in 2007, and in 2011, [40] validated the Italian version. The WEMWBS 
measures well-being, which is understood as positive mental health, including affective, cognitive, and well-functioning psychological aspects. The 12-item WEMWBS has 5 response categories, which are summed to provide a single score, and contains only positive aspects of mental health through a positive formulation of all items. The scale is scored by summing the responses to each item answered on a 1 to 5 Likert scale. The minimum scale score is 14 and the maximum is 70. The internal validity is $\alpha=0.90$. The reliability of the 12-item Italian version has a value of 0.86 for (Cronbach's) alpha. Example items include: "I've been feeling confident" and "I've had energy to spare."

10. Satisfaction with Life Scale [42]: This scale, originally developed by [43], assesses global life satisfaction through five scaled items on a 7-point rating scale ranging from 1 = strongly disagree to 7 = strongly agree. Concerning the content formulation, items 1 to 3 refer to satisfaction with the present, and items 4 and 5 to satisfaction with the past. The scale exhibited reliability and validity in various contexts and cultures. The Italian translation of this scale was validated by [42] and its reliability is $\alpha=0.85$. Example items are: "In most ways my life is close to my ideal" and "I am satisfied with my life."

11. Positive Affect Negative Affect Scale (PANAS) [44]: We used the Italian version of this scale [45], which was developed from the original scale of [44]. This self-report scale assesses two independent dimensions of positive (PA) and negative affect (NA). Participants were asked to rate how much they experienced each of the 20 emotions on a 5-point scale, ranging from $1=$ "very slightly" to $5=$ "very much." The PA scale consists of the items excited, enthusiastic, concentrated, inspired, and determined, whereas the NA consists of the items distressed, upset, scared, nervous, and afraid. The internal reliability coefficient of the Italian version is $\alpha=0.76$.

\subsection{Procedure}

For the experiments, an online survey was created ad hoc through Google modules that allowed us to easily send our questionnaire via the web. Participants were recruited through online posts on a social network site, as face-to-face contact was not permitted due to the anti-COVID-19 provisions. Before accessing the survey, all respondents were informed about the objectives of the study and provided electronic informed consent. The data refers to the pre-peak time (from 6 April to 12 April 2020-active cases of the disease: 93,187-102,253). To conduct a comprehensive analysis during the lockdown period, we administered an online survey that was made up of different scales to evaluate the psychological antecedents of reported compliance in the Italian population. The sample of the study was recruited through a voluntary and anonymous census online in the pre-peak phase. For the recruitment, a series of messages were prepared and shared on social networks through the researchers' accounts. In addition, the data collection was promoted through University of Florence mailing lists and snowball sampling. Although the dissemination of the survey through a social network could have led to sampling bias (e.g., social network users), as evidenced by the average age registered, this method can nonetheless contribute positively to promoting the real self-disclosure [46] and can reduce the impact of social desirability [47].

\subsection{Data Analysis}

All data were analyzed using SPSS 25.0 (IBM Inc., New York, NY, USA). As the first step, we produced descriptive statistics according to the measurement scale for the variables involved in the subsequent inferential phase. For the quantitative data, indices of central tendency (i.e., average) and variability (minimum, maximum, standard deviation) were produced. For the qualitative data (e.g., the reported compliance levels for each provision), we relied on percentages. The reported compliance relationship with socio-demographic variables was explored through the chi-square test. As for the effect size, Cramer's V and phi coefficients were calculated according to the table size when the chi-square test was statistically significant. 
Psychological antecedents of reported compliance, as well as the reported compliance relationships with well-being and emotional activations, were analyzed using the independent sample Student's $t$-test after checking the analysis's assumptions (skewness and kurtosis values). Cohen's d was calculated to determine each effect size.

\subsection{Ethical Considerations}

The ethical principles set out in the Helsinki Declaration were followed and the study was approved by the ethical commission of the University of Florence (approved protocol number: 0092811). The questionnaires were administered to the participants according to the Italian law's requirements of privacy and informed consent (Law Decree DL-101/2018), EU regulation (2016/699), and APA guidelines. The participants were able to leave the survey at any moment and in total anonymity, unlike other methods that provide a mandatory response to the survey (i.e., ISTAT investigation regulated by Legislative Decree 322/1989, art. 7). We considered only data with a complete set of responses. No personal or sensible data were collected during the data collection.

\section{Results}

\subsection{Descriptive Statistics}

As a first step, we provided a description of the sample according to the selected sociodemographic variables (Table 1 ).

Table 1. Sample characteristics for our Italian sample.

\begin{tabular}{lc}
\hline Variable & Mean (SD) or $\%$ \\
\hline Age & $27.88(10.33)$ \\
\hline Gender & $16.3 \%$ \\
\hline Male & $83.7 \%$ \\
\hline Female & \\
\hline Yearly Income (EUR) & $52.8 \%$ \\
\hline$<10 \mathrm{k}$ & $38.6 \%$ \\
\hline $10-40 \mathrm{k}$ & $6.1 \%$ \\
\hline $40-70 \mathrm{k}$ & $2.1 \%$ \\
\hline $70-120 \mathrm{k}$ & $0.4 \%$ \\
\hline$>120 \mathrm{k}$ & \\
\hline Education & $6.7 \%$ \\
\hline Secondary school & $49.9 \%$ \\
\hline High school & $22.0 \%$ \\
\hline Bachelor degree & $16.9 \%$ \\
\hline Master's degree & $2.8 \%$ \\
\hline University master & $1.8 \%$ \\
\hline Ph.D. or other specialization & \\
\hline Marital Status & $37.5 \%$ \\
\hline Single & $39.3 \%$ \\
\hline In a relationship (without cohabiting) & $21.4 \%$ \\
\hline Married or cohabiting & $0.3 \%$ \\
\hline Divorced & \\
\hline Widowed & \\
\hline & \\
\hline
\end{tabular}


Table 1. Cont.

\begin{tabular}{lc}
\hline Variable & Mean (SD) or $\%$ \\
\hline Occupational Status & \\
\hline Unemployed & $15.1 \%$ \\
\hline Student & $48.4 \%$ \\
\hline Self-employed & $10.0 \%$ \\
\hline Public employee & $5.4 \%$ \\
\hline Permanent employee & $19.4 \%$ \\
\hline Retired & $1.7 \%$ \\
\hline Housing Condition ${ }^{*}$ & \\
\hline Alone & $8.4 \%$ \\
\hline With partner & $20.4 \%$ \\
\hline With family & $67.2 \%$ \\
\hline Friends/Roommates & $9.5 \%$ \\
\hline Elderly or frail people & $10.3 \%$ \\
\hline Children & $8.6 \%$ \\
\hline Knowing Someone Infected ${ }^{*}$ & \\
\hline No & $54.3 \%$ \\
\hline Acquientance & $34.8 \%$ \\
\hline Family member & $7.0 \%$ \\
\hline Friend & $9.7 \%$ \\
\hline Yes, me & $0.8 \%$ \\
\hline Note categories were not mutually exclusive. & \\
\hline
\end{tabular}

As we can grasp from Table 1, our sample was composed mainly of adult females. Most of the participants were students (48.4\%), with a yearly income lower than $40 \mathrm{k}$ EUR (91.4\%), had a high-school diploma or higher (93.4\%), and lived with their family (67.2\%). More variability was observed for the current marital status.

We now present the descriptive statistics relating to people's reported compliance to the provisions issued by the Italian Ministry of Health against the COVID-19 pandemic during the peak time (from 6 April to 12 April). In particular, Figure 1 shows how many people have complied with each anti-COVID behavioral rule.

Furthermore, we collected the degree of information about the prescriptions and the motivation to follow the norms to protect other people or themselves. Descriptive analysis showed that more than $80 \%$ of respondents claimed to be well informed about the antiCOVID prescriptions and reported adhering to the norms to protect others (73.8\%). Our sample claimed that they washed their hands frequently during the COVID-19 pandemic (about $87 \%$ ), avoided taking antibiotics or antiviral medication unless prescribed by a physician (95.7\%), and almost all the respondents (91.5\%) avoided close contact with people suffering from acute respiratory infections. Face masks were reported to be used by $77 \%$ of the respondents. Finally, almost all participants (98.1\%) reported avoiding going to the emergency room, hospital, or clinic during the peak in the case of doubt about their health conditions.

In general, our participants appeared to be, on average, very compliant if we considered that they obtained total scores higher than the theoretical mean on reported compliance (35.4 versus 24.0).

The descriptive statistics related to personality, self-efficacy, change motivation, risk perception, well-being measures, social connectedness, and positive/negative affect are shown in the Appendix A in Table A1. 


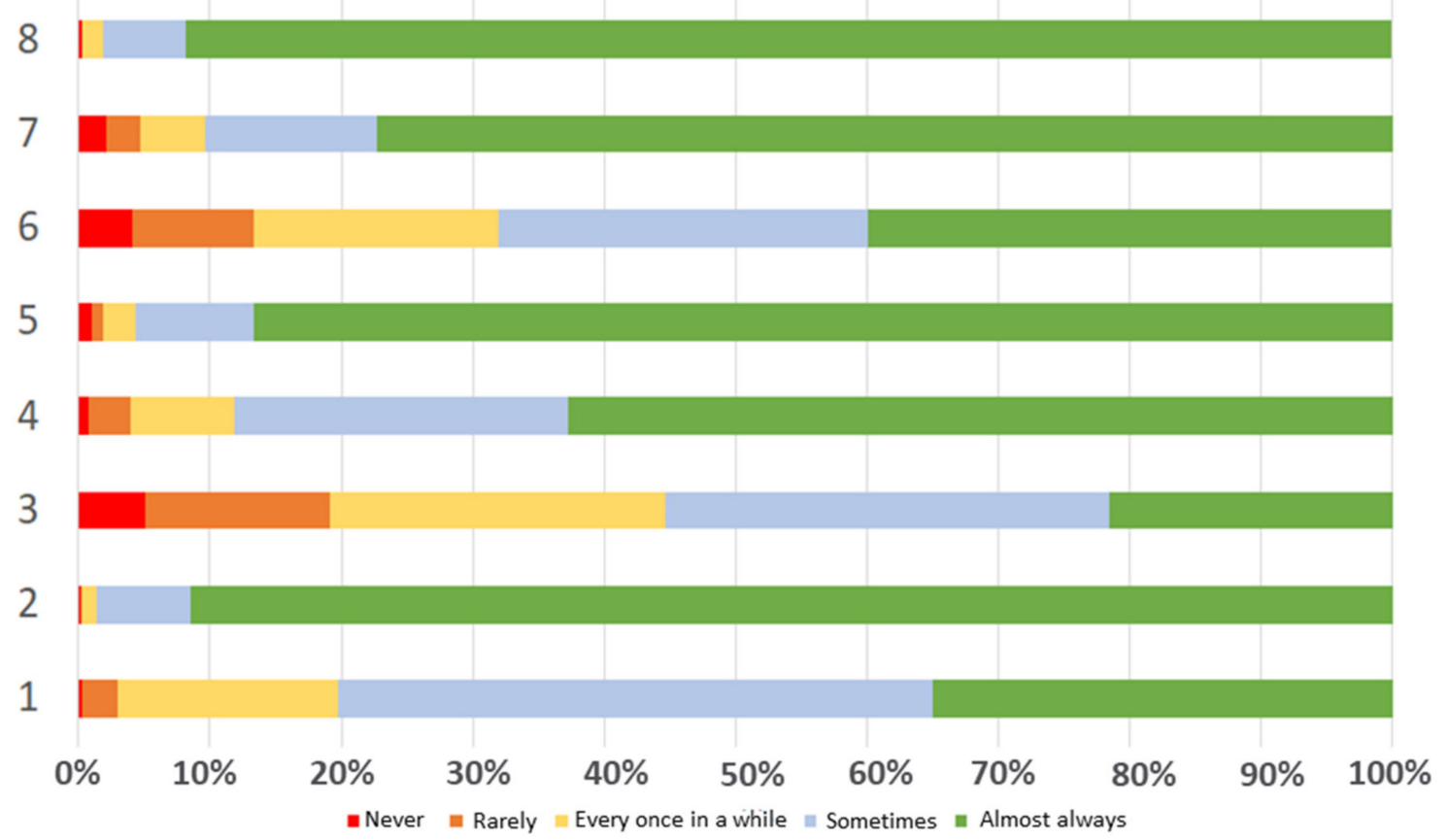

Figure 1. Reported compliance levels across provisions. The figure displays the reported compliance levels to the provisions issued by the Italian Ministry of Health against the COVID-19 pandemic slightly before the peak. $1=$ wash hands often with an alcohol-based gel; 2 = avoid close contact with people suffering from acute respiratory infections; $3=$ do not touch your eyes, nose, and mouth with hands; 4 = cover your mouth and nose with a tissue, hands, or with arms whenever you cough or sneeze; $5=$ avoid taking antibiotics or antiviral medication unless prescribed by a physician; $6=$ clean surfaces with chlorine- or alcohol-based disinfectants; 7 = use a face mask if you go out or if you are caring for people who are ill; $8=$ in case of doubts do not go to the emergency room, hospital, or clinic, but contact your doctor.

\subsection{Socio-Demographic Characteristics and Reported Compliance}

In this subsection, we present all those socio-demographic characteristics that did not appear to affect people's reported compliance. The chi-square test was employed to measure the association between these variables. To proceed with the analyses, we discretized the overall reported compliance into two different levels according to the median since the reported compliance was not normally distributed.

In general, people's annual income appeared to be unrelated to the reported compliance $\left(\chi^{2}{ }_{(4)}=4.65, p=0.33\right)$. Moreover, several housing situations did not appear to affect the individuals' reported compliance: living on their own $\left(\chi^{2}{ }_{(1)}=0.93, p=0.33\right)$ or with family $\left(\chi_{(1)}^{2}=0.006, p=0.94\right)$, a partner $\left(\chi_{(1)}^{2}=3.16, p=0.075\right)$, frail elderly $\left(\chi^{2}{ }_{(1)}=0.61, p=0.44\right)$, or children $\left(\chi^{2}(1)=2.97, p=0.085\right)$ did not produce higher or lower reported compliances. Thus, these housing situations were not facilitating factors for reported compliance.

Knowing someone that was infected with SARS-CoV-2 did not appear to matter either $\left(\chi^{2}{ }_{(1)}=0.29, p=0.59\right)$, not even if this someone was an acquaintance $\left(\chi^{2}{ }_{(1)}=0.24, p=0.62\right)$, a family member $\left(\chi^{2}{ }_{(1)}=0.016, p=0.90\right)$, or themself $\left(\chi^{2}{ }_{(1)}=0.55, p=0.46\right)$. Finally, owning a pet animal did not produce a different level of reported compliance $\left(\chi^{2}{ }_{(1)}=0.10, p=0.75\right)$. Other socio-demographic characteristics instead appeared to be connected to the reported compliance. To define the effect size of each of these characteristics, we relied on Cramer's $\mathrm{V}$ and phi coefficients. The phi coefficient is a measure of the strength of an association between two categorical variables in a $2 \times 2$ contingency table. It is calculated by taking the chi-square value, dividing it by the sample size, and then taking the square root of this value. Cramer's V is an alternative measure to the phi coefficient with contingency tables of varying sizes. Phi coefficients range from -1 and +1 , while Cramer's V ranges from 0 to 1 (perfect association) and both coefficients can be interpreted roughly using Pearson's $r$ coefficients rule of thumb [48]: a negligible correlation for coefficient lower than I0.19|, a 
weak correlation for values between $|0.20|$ and $|0.39|$, a moderate correlation for $r$ values ranging from $|0.40|$ to $|0.59|$, a strong correlation for coefficients between $|0.60|$ and $|0.79|$, and a very strong correlation for values higher than $|0.80|$.

Gender did affect the reported compliance $\left(\chi^{2}{ }_{(1)}=17.93, p=0.001 ; \Phi=0.11, p=0.001\right)$. Indeed, among males, the prevalence of reported high-compliance individuals was $31.6 \%$, while for females, we observed that $46 \%$ followed the anti-COVID rules strictly. Participants' age affected the reported compliance as well $\left(\chi^{2}{ }_{(1)}=17.24, p=0.001 ; \Phi=0.10\right.$, $p=0.001)$. Older people appeared to be more represented among the highly compliant individuals (49\% of older people had a high reported compliance compared with $38.5 \%$ of younger participants).

Participants' education also mattered $\left(\chi_{(5)}^{2}=12.32, p=0.031 ; \mathrm{V}=0.09, p=0.03\right)$. Lower education levels seemed to be associated with weaker reported compliance. A total of $37.5 \%$ of people who had a secondary school diploma, $44.1 \%$ of those who held a high school diploma, and $38.1 \%$ of bachelor degrees followed prescriptions more, while for higher education levels, we mostly observed a larger proportion (51\% for master's degree, $51.2 \%$ for university master, and $42.9 \%$ for Ph.D.). Even marital status seemed to affect people's reported compliance $\left(\chi^{2}{ }_{(5)}=19.32, p=0.001 ; \mathrm{V}=0.11, p=0.001\right)$. In particular, singles appeared to follow the anti-contagion prescriptions much less than others. Only $37.6 \%$ of them frequently followed recommendations, while engaged people without cohabitation (44.9\%), married/cohousing individuals (50.8\%), divorced (60.9\%), and widowed $(60 \%)$ participants appeared to more strictly adhere to the anti-contagion rules. Occupational status appeared to also influence the anti-COVID reported compliance dynamics $\left(\chi_{(4)}^{2}=18.08, p=0.003 ; \mathrm{V}=0.11, p=0.003\right)$. Retired $(61.5 \%)$ and unemployed people $(52.8 \%)$ were more likely to follow the indicated prescriptions. The students instead appeared as those that adhered to the prescriptions less (39.3\%), while no great differences in reported compliance were detected among self-employed $(46.8 \%)$, public employees $(41.7 \%)$, and permanent employees $(45 \%)$. Although several housing situations appeared to be unrelated to the reported compliance, as we mentioned earlier, living with roommates appeared to be a risk factor $\left(\chi^{2}{ }_{(1)}=4.14, p=0.04 ; \Phi=-0.05, p=0.04\right)$. Those who had at least one roommate complied a lot only in $35.8 \%$ of the cases, while people with a different housing situation complied a lot in around $44.5 \%$ of the cases. Finally, while knowing other people infected with SARS-CoV-2, in general, did not affect the reported compliance, being aware that a friend had the virus increase people's reported compliance $\left(\chi^{2}{ }_{(1)}=9.67\right.$, $p=0.002 ; \Phi=0.08, p=0.002$ ). If our participants did not have a friend with a SARS-CoV-2 infection, their reported compliance was $42.4 \%$, while those who knew that one of their friends contracted the virus, followed the prescriptions in 55.6\% of cases. An overview of the relationships investigated as part of the socio-demographic characteristics regarding people's reported compliance is presented in Table 2.

\subsection{Psychological Variables and Reported Compliance}

Psychological antecedents of the reported compliance were analyzed using the independent sample Student's $t$-test. In this way, we were able to compare the psychological characteristics of people that complied with the anti-COVID prescriptions more with those of the individuals that followed them less. The results of the comparison are shown in Table 3. Moreover, for each difference, we calculated the effect size. Cohen's d was calculated using the $t$ values coming from the independent sample Student's $t$-test: $2 t / \sqrt{(d f)}$. For the sake of clarity, we specify that a small effect size corresponded to a Cohen's d coefficient higher than 0.2 , a medium effect size corresponded to coefficient values higher than 0.5 , and a large effect size corresponded to values above 0.8 [49]. 
Table 2. Summary of the socio-demographic relationships with the reported compliance.

\begin{tabular}{lccc}
\hline Variable & $\chi^{2}$ & $p$ & Effect Size $^{\mathbf{a}}$ \\
\hline Age & 17.24 & 0.001 & 0.10 \\
\hline Gender & 17.93 & 0.001 & 0.11 \\
\hline Yearly Income & 4.65 & 0.33 & n.c. \\
\hline Education & 12.32 & 0.031 & 0.09 \\
\hline Marital Status & 19.32 & 0.001 & 0.11 \\
\hline Occupational Status & 18.08 & 0.003 & 0.11 \\
\hline Housing Condition & & & n.c. \\
\hline Alone & 0.93 & 0.33 & n.c. \\
\hline With partner & 3.16 & 0.075 & n.c. \\
\hline With family & 0.006 & 0.94 & n.c. \\
\hline Friends/roommates & 4.14 & 0.04 & n.c. \\
\hline Elderly or frail people & 0.61 & 0.44 & \\
\hline Children & 2.97 & 0.09 & n.c. \\
\hline Knowing Someone Infected & & & n.c. \\
\hline No & 0.29 & 0.59 & n.c. \\
\hline Acquaintance & 0.24 & 0.62 & 0.08 \\
\hline Family member & 0.016 & 0.90 & n.c \\
\hline Friend & 9.67 & 0.002 & \\
\hline Yes, me & 0.55 & 0.46 & \\
\hline Note & & & \\
\hline
\end{tabular}

Note: ${ }^{a}=$ effect size according to the contingency tables size; n.c. = not computed due to there not being a statistically significant result.

Table 3. High versus low reported compliance differences regarding psychological characteristics.

\begin{tabular}{|c|c|c|c|c|c|}
\hline Variable & Reported Compliance Level & $n$ & Mean & Student's $t$ & Cohen's $d$ \\
\hline \multirow{2}{*}{ Agreeableness } & $<$ Median & 876 & 7.26 & \multirow{2}{*}{$-4.48^{* * *}$} & \multirow[b]{2}{*}{-0.26} \\
\hline & >Median & 680 & 7.61 & & \\
\hline \multirow{2}{*}{ Conscientiousness } & $<$ Median & 876 & 7.47 & \multirow{2}{*}{$-6.62^{* * *}$} & \multirow{2}{*}{-0.39} \\
\hline & $>$ Median & 680 & 8.06 & & \\
\hline \multirow{2}{*}{ Neuroticism } & $<$ Median & 876 & 6.28 & \multirow{2}{*}{$2.38^{*}$} & \multirow{2}{*}{0.14} \\
\hline & $>$ Median & 680 & 6.03 & & \\
\hline \multirow{2}{*}{ Self-efficacy } & $<$ Median & 876 & 34.86 & \multirow{2}{*}{$-4.85^{* * *}$} & \multirow{2}{*}{-0.29} \\
\hline & $>$ Median & 680 & 36.46 & & \\
\hline \multirow{2}{*}{$\begin{array}{c}\text { Risk: } \\
\text { Perceived severity }\end{array}$} & $<$ Median & 876 & 11.69 & \multirow{2}{*}{$-8.21^{* * *}$} & \multirow[b]{2}{*}{-0.48} \\
\hline & $>$ Median & 680 & 12.49 & & \\
\hline \multirow{2}{*}{$\begin{array}{c}\text { Risk: } \\
\text { Coping efficacy }\end{array}$} & $<$ Median & 876 & 3.49 & \multirow{2}{*}{$0.97^{\mathrm{ns}}$} & \multirow[b]{2}{*}{0.06} \\
\hline & $>$ Median & 680 & 3.44 & & \\
\hline \multirow{2}{*}{$\begin{array}{c}\text { Risk: } \\
\text { Likelihood of infection }\end{array}$} & $<$ Median & 876 & 2.62 & \multirow{2}{*}{$-2.55^{* *}$} & \multirow{2}{*}{-0.15} \\
\hline & $>$ Median & 680 & 2.74 & & \\
\hline Risk: & $<$ Median & 876 & 15.41 & \multirow{2}{*}{$-7.34^{* * *}$} & \multirow{2}{*}{-0.43} \\
\hline Affect/Concern & >Median & 680 & 17.16 & & \\
\hline Risk: & $<$ Median & 876 & 6.59 & \multirow{2}{*}{$-2.28 *$} & \multirow{2}{*}{-0.13} \\
\hline Probability & $>$ Median & 680 & 6.79 & & \\
\hline \multirow{2}{*}{$\begin{array}{c}\text { Risk: } \\
\text { Consequence }\end{array}$} & $<$ Median & 876 & 6.07 & \multirow{2}{*}{$-3.43^{* * *}$} & \multirow{2}{*}{-0.20} \\
\hline & $>$ Median & 680 & 6.44 & & \\
\hline
\end{tabular}


Among the five-factor model traits, agreeableness and conscientiousness seemed to be more strongly associated with reported adherence to the anti-COVID prescriptions. Conversely, people who struggled with negative emotional arousal regulation (i.e., neuroticism) tended to follow the behavioral recommendations less. Instead, people's extraversion and openness appeared unrelated to reported compliance. Another fairly stable psychological characteristic, such as self-efficacy, was associated with reported compliance. As we expected, risk perception was associated with people's reported compliance. In general, higher levels of risk perception were related to stronger reported compliance. In particular, the cognitively perceived severity seemed to be the strongest factor affecting reported compliance, together with the concern toward COVID-19. The motivation for change appeared to be associated with reported compliance. Since the variable was non-normally distributed, we relied on the chi-square test and the phi coefficient $\left(\chi^{2}{ }_{(1)}=82.90, p=0.001 ; \Phi=0.23, p=0.001\right)$. Individuals that were more motivated toward change seemed to be more represented among the highly compliant people (52.6\%) relative to those that were less motivated $(29.0 \%)$.

\subsection{Reported Compliance Associations with Well-Being and Social Connectedness}

In this subsection, we present the results regarding the relationship between people's compliance and well-being, also considering social connectedness, which can be threatened due to quarantine. These results are shown in Table 4.

Table 4. High versus low reported compliance differences regarding well-being and social connectedness.

\begin{tabular}{|c|c|c|c|c|c|}
\hline Variable & Reported Compliance Level & $n$ & Mean & Student's $t$ & Cohen's $d$ \\
\hline \multirow{2}{*}{ WEMWBS } & $<$ Median & 876 & 40.60 & \multirow{2}{*}{$-5.53^{* * *}$} & \multirow[b]{2}{*}{-0.28} \\
\hline & $>$ Median & 680 & 42.45 & & \\
\hline \multirow{2}{*}{ SWL } & $<$ Median & 876 & 15.39 & \multirow{2}{*}{$-3.81^{* * *}$} & \multirow{2}{*}{-0.19} \\
\hline & $>$ Median & 680 & 16.28 & & \\
\hline \multirow{2}{*}{ Social connectedness } & $<$ Median & 876 & 81.87 & \multirow{2}{*}{$-4.39^{* * *}$} & \multirow{2}{*}{-0.22} \\
\hline & $>$ Median & 680 & 85.60 & & \\
\hline
\end{tabular}

Note: ${ }^{* * *}=p<0.001$; WEMWBS $=$ Warwick-Edinburgh Mental Well-Being Scale; SWL = Satisfaction with Life.

The people that followed more anti-COVID rules were those that experienced higher states of wellbeing (as measured using the WEMWBS and SWL) and had a higher subjective awareness of being in a close relationship with their social world.

\subsection{Emotional Activations Related to Reported Compliance}

Based on the literature, people's affective experiences can influence their reported compliance. For this reason, we investigated whether positive and negative activation was different between people that complied more or less with the anti-COVID prescriptions. First, we compared people's overall scores on both the positive and negative aspects.

As we can gather from Table 5, a positive activation appeared to be associated with a higher level of reported compliance. Instead, experiencing unpleasant activation seemed to be not related to the reported compliance. Nonetheless, we deepened our analysis by accounting for all positive (Table 6) and negative (Table 7) descriptors.

Table 5. High versus low reported compliance differences regarding the PANAS total scores.

\begin{tabular}{|c|c|c|c|c|c|}
\hline Variable & Reported Compliance Level & $n$ & Mean & Student's $t$ & Cohen's $d$ \\
\hline Positive affect & $\begin{array}{l}<\text { Median } \\
>\text { Median }\end{array}$ & $\begin{array}{l}876 \\
680\end{array}$ & $\begin{array}{l}29.34 \\
31.24\end{array}$ & $-5.10^{* * *}$ & -0.26 \\
\hline Negative affect & $\begin{array}{l}<\text { Median } \\
>\text { Median }\end{array}$ & $\begin{array}{l}876 \\
680\end{array}$ & $\begin{array}{l}24.24 \\
23.84\end{array}$ & $1.10^{\mathrm{ns}}$ & 0.05 \\
\hline
\end{tabular}


Table 6. High versus low reported compliance differences regarding positive affect.

\begin{tabular}{|c|c|c|c|c|c|}
\hline Variable & Reported Compliance Level & $n$ & Mean & Student's $t$ & Cohen's $d$ \\
\hline \multirow[b]{2}{*}{ Determined } & $<$ Median & 876 & 3.13 & \multirow[b]{2}{*}{$-3.51^{* * *}$} & \multirow[b]{2}{*}{-0.17} \\
\hline & $>$ Median & 680 & 3.31 & & \\
\hline \multirow{2}{*}{ Active } & $<$ Median & 876 & 3.00 & \multirow{2}{*}{$-4.71^{* * *}$} & \multirow{2}{*}{-0.24} \\
\hline & $>$ Median & 680 & 3.23 & & \\
\hline \multirow{2}{*}{ Interested } & $<$ Median & 876 & 3.29 & \multirow{2}{*}{$-5.04^{* * *}$} & \multirow{2}{*}{-0.26} \\
\hline & $>$ Median & 680 & 3.54 & & \\
\hline \multirow{2}{*}{ Attentive } & $<$ Median & 876 & 3.18 & \multirow{2}{*}{$-5.74^{* * *}$} & \multirow{2}{*}{-0.29} \\
\hline & >Median & 680 & 3.47 & & \\
\hline \multirow{2}{*}{ Enthusiastic } & $<$ Median & 876 & 2.75 & \multirow{2}{*}{$-2.48^{*}$} & \multirow{2}{*}{-0.13} \\
\hline & $>$ Median & 680 & 2.89 & & \\
\hline \multirow{2}{*}{ Concentrated } & $<$ Median & 876 & 2.78 & \multirow{2}{*}{$-5.31^{* * *}$} & \multirow{2}{*}{-0.27} \\
\hline & >Median & 680 & 3.05 & & \\
\hline \multirow{2}{*}{ Strong } & $<$ Median & 876 & 2.94 & \multirow{2}{*}{$-3.64^{* * *}$} & \multirow{2}{*}{-0.18} \\
\hline & $>$ Median & 680 & 3.13 & & \\
\hline \multirow{2}{*}{ Inspired } & $<$ Median & 876 & 2.89 & \multirow{2}{*}{$-2.22 *$} & \multirow{2}{*}{-0.11} \\
\hline & >Median & 680 & 3.01 & & \\
\hline \multirow{2}{*}{ Proud } & $<$ Median & 876 & 2.87 & \multirow{2}{*}{$-3.60^{* * *}$} & \multirow{2}{*}{-0.18} \\
\hline & $>$ Median & 680 & 3.08 & & \\
\hline
\end{tabular}

Note: ${ }^{* * *}=p<0.001,^{*}=p<0.05$.

Table 7. High versus low reported compliance differences regarding negative affect.

\begin{tabular}{|c|c|c|c|c|c|}
\hline Variable & Reported Compliance Level & $n$ & Mean & Student $t$ & Cohen's $d$ \\
\hline Scared & $\begin{array}{l}<\text { Median } \\
>\text { Median }\end{array}$ & $\begin{array}{l}876 \\
680\end{array}$ & $\begin{array}{l}2.41 \\
2.55\end{array}$ & $-2.58^{* *}$ & -0.13 \\
\hline Guilty & $\begin{array}{l}<\text { Median } \\
>\text { Median }\end{array}$ & $\begin{array}{l}876 \\
680\end{array}$ & $\begin{array}{l}1.54 \\
1.45\end{array}$ & 1.94 * & 0.10 \\
\hline Ashamed & $\begin{array}{l}<\text { Median } \\
>\text { Median }\end{array}$ & $\begin{array}{l}876 \\
680\end{array}$ & $\begin{array}{l}1.56 \\
1.41\end{array}$ & $3.36^{* * *}$ & 0.17 \\
\hline Irritable & $\begin{array}{l}<\text { Median } \\
>\text { Median }\end{array}$ & $\begin{array}{l}876 \\
680\end{array}$ & $\begin{array}{l}2.91 \\
2.80\end{array}$ & 1.94 * & 0.10 \\
\hline Hostile & $\begin{array}{l}<\text { Median } \\
>\text { Median }\end{array}$ & $\begin{array}{l}876 \\
680\end{array}$ & $\begin{array}{l}1.97 \\
1.77\end{array}$ & $4.02 * * *$ & 0.20 \\
\hline
\end{tabular}

Note: ${ }^{* * *}=p<0.001,{ }^{* *}=p<0.01,{ }^{*}=p<0.05$

In general, people that felt more active, interested, attentive, and concentrated were the ones that reported complying more with the anti-COVID rules. Smaller differences were detectable regarding determined, enthusiastic, strong, inspired, and proud descriptors. Even in these cases, people appeared to more strictly adhere to anti-COVID prescriptions.

More mixed and moderate results came from the negative descriptors' analysis. More scared individuals tended to follow more anti-contagion prescriptions, whereas other negative activations, such as shame, hostility, irritation, and guilt, appeared to be related to a lower level of reported compliance.

Finally, we proceeded to systematize the results obtained concerning both the sociodemographic and psychological variables in Figure 2 to highlight the different magnitudes of the effects related to the reported compliance. 


\section{PSYCHOLOGICAL VARIABLES}

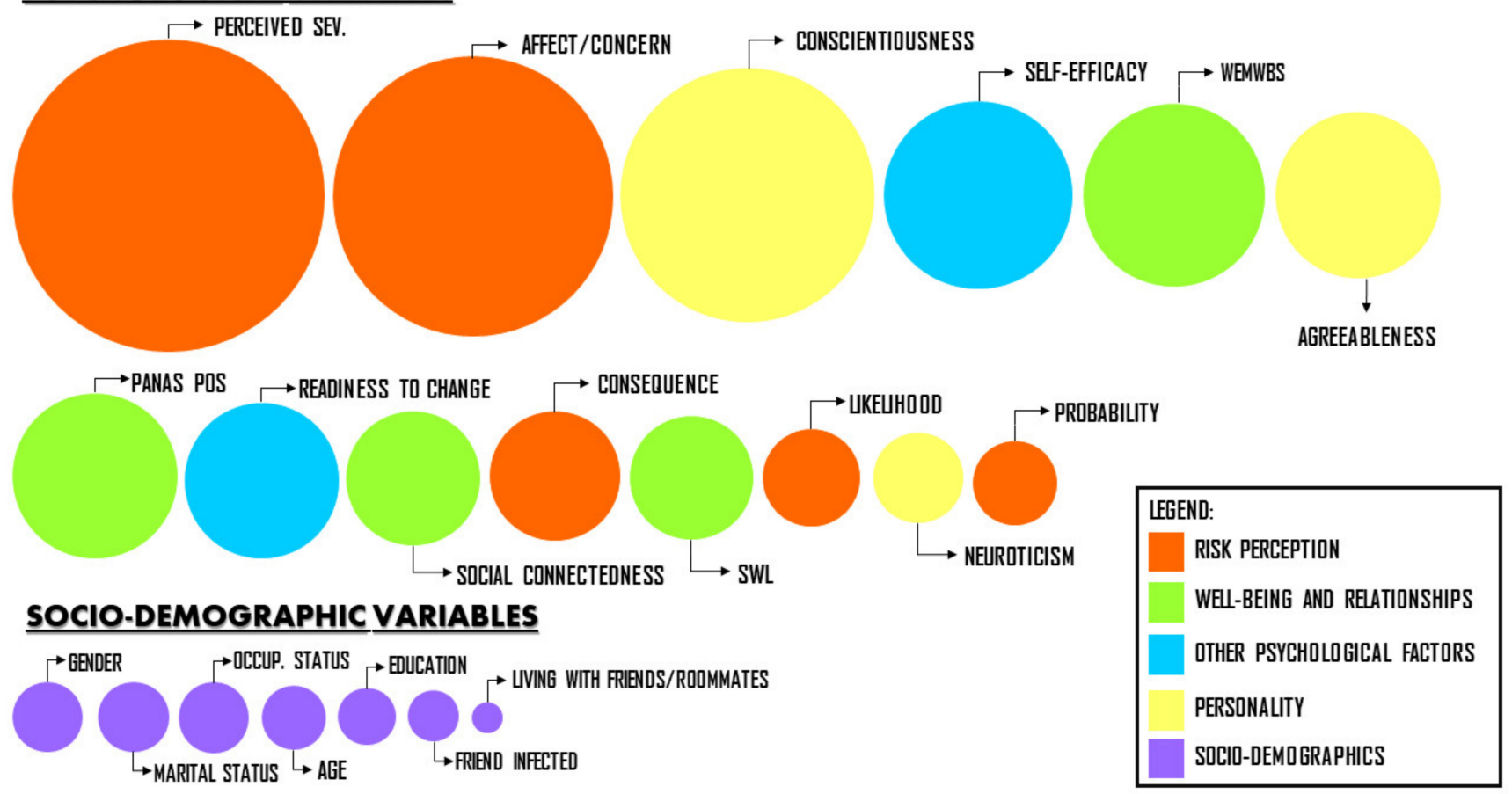

Figure 2. Summary of the socio-demographic and psychological variables associated with reported compliance. Each circle size represents the strength of the relationship between reported compliance and the other variables.

\section{Discussion}

Using an Italian sample, this study aimed to investigate the psychological profile of people's reported compliance to the provisions issued by the Italian Ministry of Health against the COVID-19 pandemic. Findings from our study indicated that in Italy, after a month of lockdown, the reported compliance was in general high, with some exceptions. Indeed, the reported adherence with behavioral norms varied across the provisions, although almost all of the respondents appeared to be, on average, very compliant with dispositions, which was also highlighted by the Istat report published on 25 May 2020 [50]. As underlined in the study by Bogg and Miland [21], the variations to norms adherence can be partially explained by individual differences, such as personality, motivation, healthrelated beliefs, and perceptions. To identify the characteristics of the person who complied with anti-contagion dispositions, we proceeded to compare our results to the studies that guided us in the selection of these observables. Non-single females and older people with higher education showed higher reported adherence to norms but with modest values (always under the $5 \%$ of variance), in line with the results of Kooistra and colleagues and Van Rooij and colleagues [18,19]. Surprisingly, the housing situation (e.g., living with children, elders, or frail people) did not significantly affect the reported compliance, and neither did knowing someone infected with SARS-CoV-2 (except for a friend). Our study also provided evidence of the impact of psychological dimensions on the reported compliance dynamics. In line with the literature, a higher level of people's risk perception promoted a stronger adherence to the anti-COVID prescriptions [17-19,25-27]. In particular, the sub-dimensions of cognitive perceived severity and concern toward COVID-19 seemed to be more tied to reported compliance than coping efficacy, which appeared independent from people's reported adherence. This independence was in line with Prati's study, which did not find an effect of such a dimension on the adoption of anti-contagion behaviors [34]. Other factors, specifically the perception of risk consequences, the likelihood of infection, and risk probability, seemed to promote reported compliance, although with a small effect size. These results corroborated other studies $[8,17,51]$ that found that individuals were 
more inclined to adopt the prescribed social norms when they evaluated the risk for their health as relevant. Regarding the association between personality traits and the reported adherence to anti-COVID prescriptions, agreeableness and conscientiousness seemed to be the stronger promoters of reported compliance/norms adherence. Furthermore, despite recent literature about social distancing (to avoid COVID-19), which showed that people with higher values of anxious and fearful traits were more inclined to comply with social distancing [8,52], in our study, a small negative effect was displayed by neuroticism in relation with the provisions issued by the Italian Ministry of Health against the COVID-19 pandemic. This result is different from the one obtained by Zettler and colleagues in which neuroticism was associated with a higher willingness to accept restrictions [20]. Conscientiousness appeared to be positively associated with both adopting social distancing [8] and behavioral norms analyzed in our study, in line with the study of Bogg and Milad [21]. These findings are also in line with a study conducted on the American population to investigate the psychological correlates of the U.S. presidential guidelines for reducing the spread of COVID-19 [21]. Although in our study, personality was linked to reported compliance, it did not seem to be the most important factor in terms of the effect size.

Self-efficacy was found to be associated with reported compliance, along with a motivation for change, which was in line with several studies $[18,19,21,24]$. Finally, we examined the associations regarding people's well-being and affective experience with reported compliance. Our findings suggested that people's psychological and psychosocial well-being was related to the reported compliance. This result appeared in line with the previous studies regarding compliance, which showed an association with both well-being and social connectedness [22,28]. Emotional activation experienced during the lockdown seemed to be an important factor that was associated with people's reported compliance. We found that 9 out of 10 positive emotions (e.g., people that feel active, interested, attentive, and concentrated) were positively associated with reported compliance, while 5 out of 10 negative emotions (e.g., hostile, irritable, ashamed, and guilty) led people to less reported adherence with the anti-COVID prescriptions. This result is different from one obtained by Van Rooij and colleagues, which highlighted how negative emotions are associated with COVID-19 mitigation measures compliance [19]. This last finding is in line with the already discussed effect of neuroticism on reported compliance. Since people with high neuroticism are strongly vulnerable to negative emotions and are unable to handle negative arousal [53], they tended to follow the prescriptions less. Notably, only feeling scared increased the reported compliance among unpleasant activations, in line with Oosterhoff and Palmer and Harper and colleagues' studies [26,27]. Currently, we are witnessing a drop in people's well-being in our societies regardless of COVID-19 [54] and epidemics may exacerbate this trend. As suggested by the literature, during epidemics, individuals may face an increase in negative psychological consequences (e.g., [55-57]). In this sense, COVID-19 appeared to be no different. Although in a recent work, the decrease in people's well-being was not evident [58], the current literature stresses that exposure to multiple COVID-19-related stressors (e.g., economic, daily-life, social, and relational stressor) can lead to negative consequences in terms of well-being and psychological distress [4,59-61]. These negative effects on people's well-being should be managed if we consider the role that well-being appears to have in our work when defining people's reported compliance.

Several limitations of this study need to be addressed. All findings were cross-sectional correlations, which do not allow for establishing a causal relationship. Another limitation associated with our study is that the increase in the familywise error rate across the reported statistical analyses was not controlled. Overall, we consider our results to be relatively preliminary and encourage replication. Replications of the study are also encouraged to overcome generalizability issues that are inherent in our exploratory study. Indeed, a greater correspondence in terms of socio-demographic characteristics between the population investigated and the sample extracted would be required to extend our study outcomes to the general population. Moreover, it should be considered that our results were related to a rather circumscribed sociodemographic cluster (i.e., mainly females, more 
educated people), which often results in having higher compliance with anti-contagion rules [62-66]. Thus, the psychological factors related to the reported compliance that we individuated in our study are extendable in a first approximation to them and hardly to other clusters. Despite some limitations, this study provides precious information about the psychological responses during the COVID-19 lockdown period in Italy.

\section{Conclusions}

Our work found that reported compliance in Italy was mostly associated with people's risk perception, personality traits (i.e., conscientiousness, agreeableness, neuroticism), selfefficacy, well-being, social connectedness, positive emotional activations, and readiness to change. In conclusion, our results seemed to suggest that the actions of national and supranational institutions (including communicative ones) should stress not only risk perception but also promote people's self-efficacy and positive emotions to plausibly generate higher levels of compliance. Thus, our results could be useful for modeling and then planning interventions for public engagement and the adoption of containment rules in the subsequent stages of the epidemic and future pandemics.

Author Contributions: Conceptualization, M.D., M.F. and A.G.; methodology, M.D. and A.G.; investigation, M.D. and M.F.; data curation, M.D. and A.G.; writing-original draft preparation, M.D., M.F. and A.G.; writing—review and editing, M.D., M.F. and A.G. All authors have read and agreed to the published version of the manuscript.

Funding: This research received no external funding.

Institutional Review Board Statement: The study was conducted according to the guidelines of the Declaration of Helsinki, and approved by the University of Florence Ethics Committee (protocol code 0092811).

Informed Consent Statement: Informed consent was obtained from all subjects involved in the study.

Data Availability Statement: The data presented in this study are available on request from the corresponding author.

Conflicts of Interest: The authors declare no conflict of interest.

\section{Appendix A}

Table A1. Descriptive statistics for personality, self-efficacy, change motivation, risk perception, well-being measures, social connectedness, and positive/negative affect.

\begin{tabular}{ccccc}
\hline Variable & Min & Max & Mean & Standard Deviation \\
\hline Extraversion & 2 & 10 & 5.94 & 2.07 \\
Agreeableness & 2 & 10 & 7.42 & 1.55 \\
Conscientiousness & 2 & 10 & 7.73 & 1.76 \\
Neuroticism & 2 & 10 & 6.17 & 2.05 \\
Openness & 2 & 10 & 6.64 & 1.64 \\
Self-Efficacy & 10 & 50 & 35.56 & 6.50 \\
Change Questionnaire & 12 & 60 & 54.16 & 1.94 \\
Risk: Perceived severity & 3 & 15 & 12.04 & 0.94 \\
Risk: Coping efficacy & 1 & 5 & 3.47 & 0.96 \\
Risk: Likelihood of infection & 1 & 5 & 2.67 & 4.74 \\
Risk: Affect/Concern & 5 & 25 & 16.18 & 1.78 \\
Risk: Probability & 2 & 10 & 6.68 & 2.15 \\
Risk: Consequence & 2 & 10 & 6.23 & 6.63 \\
WEMWBS & 12 & 60 & 41.41 & 4.62 \\
SWL & 5 & 25 & 15.78 & 16.69 \\
Social Connectedness & 22 & 120 & 83.50 & 7.36 \\
Positive Affect & 10 & 50 & 30.17 & 7.15 \\
Negative Affect & 10 & 49 & 24.07 & \\
\hline
\end{tabular}

Note: WEMWBS = Warwick-Edinburgh Mental Well-Being Scale; SWL = Satisfaction with Life. 


\section{References}

1. Wright, L.; Steptoe, A.; Fancourt, D. Predictors of self-reported adherence to COVID-19 guidelines. A longitudinal observational study of 51,600 UK adults. Lancet Reg. Health Eur. 2021, 4, 100061. [CrossRef] [PubMed]

2. Mækelæ, M.J.; Reggev, N.; Dutra, N.B.; Tamayo, R.M.; Silva-Sobrinho, R.A.; Klevjer, K.; Pfuhl, G. Perceived efficacy of COVID-19 restrictions, reactions and their impact on mental health during the early phase of the outbreak in six countries. R. Soc. Open Sci. 2020, 7, 200644. [CrossRef]

3. Ahmed, M.Z.; Ahmed, O.; Aibao, Z.; Hanbin, S.; Siyu, L.; Ahmad, A. Epidemic of COVID-19 in China and associated psychological problems. Asian J. Psychiatry 2020, 51, 102092. [CrossRef] [PubMed]

4. Domínguez-Salas, S.; Gómez-Salgado, J.; Andrés-Villas, M.; Díaz-Milanés, D.; Romero-Martín, M.; Ruiz-Frutos, C. Psychoemotional approach to the psychological distress related to the COVID-19 pandemic in Spain: A cross-sectional observational study. Healthcare 2020, 8, 190. [CrossRef] [PubMed]

5. Xiang, Y.-T.; Yang, Y.; Li, W.; Zhang, L.; Zhang, Q.; Cheung, T.; Ng, C.H. Timely mental health care for the 2019 novel coronavirus outbreak is urgently needed. Lancet Psychiatry 2020, 7, 228-229. [CrossRef]

6. Chen, B.; Li, Q.; Zhang, H.; Zhu, J.; Yang, X.; Wu, Y.; Xiong, J.; Li, F.; Wang, H.; Chen, Z. The psychological impact of COVID-19 outbreak on medical staff and the general public. Curr. Psychol. 2020, 1-9. [CrossRef]

7. Maharaj, S.; Kleczkowski, A. Controlling epidemic spread by social distancing: Do it well or not at all. BMC Public Health 2012, 12, 679. [CrossRef]

8. Abdelrahman, M. Personality traits, risk perception, and protective behaviors of arab residents of Qatar during the COVID-19 pandemic. Int. J. Ment. Health Addict 2020, 1-12. [CrossRef]

9. Briscese, G.; Lacetera, N.; Macis, M.; Tonin, M. Expectations, Reference Points, and Compliance with COVID-19 Social Distancing Measures; National Bureau of Economic Research: Cambridge, MA, USA, 2020.

10. Moran, K.R.; Valle, S.Y.D. A meta-analysis of the association between gender and protective behaviors in response to respiratory epidemics and pandemics. PLoS ONE 2016, 11, e0164541. [CrossRef]

11. Liao, Q.; Cowling, B.; Lam, W.T.; Ng, M.W.; Fielding, R. Situational awareness and health protective responses to pandemic influenza A (H1N1) in Hong Kong: A cross-sectional study. PLoS ONE 2010, 5, e13350. [CrossRef]

12. Strickhouser, J.E.; Zell, E.; Krizan, Z. Does personality predict health and well-being? A metasynthesis. Health Psychol. Off. J. Div. Health Psychol. Am. Psychol. Assoc. 2017, 36, 797-810. [CrossRef] [PubMed]

13. Bacon, A.M.; Corr, P.J. Coronavirus (COVID-19) in the United Kingdom: A personality-based perspective on concerns and intention to self-isolate. Br. J. Health Psychol. 2020, 25, 839-848. [CrossRef] [PubMed]

14. Blagov, P.S. Adaptive and dark personality in the COVID-19 pandemic: Predicting health-behavior endorsement and the appeal of public-health messages. Soc. Psychol. Personal. Sci. 2020, 12, 697-707. [CrossRef]

15. Poletti, P.; Ajelli, M.; Merler, S. Risk perception and effectiveness of uncoordinated behavioral responses in an emerging epidemic. Math. Biosci. 2012, 238, 80-89. [CrossRef] [PubMed]

16. Leppin, A.; Aro, A.R. Risk perceptions related to SARS and avian influenza: Theoretical foundations of current empirical research. Int. J. Behav. Med. 2009, 16, 7-29. [CrossRef]

17. Wise, T.; Zbozinek, T.D.; Michelini, G.; Hagan, C.C.; Mobbs, D. Changes in Risk Perception and Self-Reported Protective Behaviour during the First Week of the COVID-19 Pandemic in the United States. R. Soc. Open Sci. 2020, 7, 200742. [CrossRef]

18. Kooistra, E.B.; Reinders Folmer, C.; Kuiper, M.E.; Olthuis, E.; Brownlee, M.; Fine, A.; van Rooij, B. Mitigating COVID-19 in a Nationally Representative UK Sample: Personal Abilities and Obligation to Obey the Law Shape Compliance with Mitigation Measures; Social Science Research Network: Rochester, NY, USA, 2020.

19. Van Rooij, B.; de Bruijn, A.L.; Reinders Folmer, C.; Kooistra, E.B.; Kuiper, M.E.; Brownlee, M.; Olthuis, E.; Fine, A. Compliance with COVID-19 Mitigation Measures in the United States; Social Science Research Network: Rochester, NY, USA, 2020.

20. Zettler, I.; Schild, C.; Lilleholt, L.; Böhm, R. The role of personality in COVID-19 related perceptions, evaluations, and behaviors: Findings across five samples, nine traits, and 17 criteria. PsyArXiv Prepr. 2020, 10, 19485506211001680. [CrossRef]

21. Bogg, T.; Milad, E. Demographic, personality, and social cognition correlates of coronavirus guideline adherence in a U.S. Sample. Health Psychol. 2020, 39, 1026. [CrossRef] [PubMed]

22. Charoenwong, B.; Kwan, A.; Pursiainen, V. Social connections with COVID-19-affected areas increase compliance with mobility restrictions. Sci. Adv. 2020, 6, eabc3054. [CrossRef] [PubMed]

23. Clemens, K.S.; Matkovic, J.; Faasse, K.; Geers, A.L. The role of attitudes, affect, and income in predicting COVID-19 behavioral intentions. Front. Psychol. 2021, 11, 3654. [CrossRef]

24. Reinders Folmer, C.; Kuiper, M.E.; Olthuis, E.; Kooistra, E.B.; de Bruijn, A.L.; Brownlee, M.; Fine, A.; van Rooij, B. Compliance in the 1.5 Meter Society: Longitudinal Analysis of Citizens' Adherence to COVID-19 Mitigation Measures in a Representative Sample in the Netherlands; Social Science Research Network: Rochester, NY, USA, 2020.

25. Ahorsu, D.K.; Lin, C.-Y.; Imani, V.; Saffari, M.; Griffiths, M.D.; Pakpour, A.H. The fear of COVID-19 scale: Development and initial validation. Int. J. Ment. Health Addict. 2020, 1-9. [CrossRef]

26. Harper, C.A.; Satchell, L.P.; Fido, D.; Latzman, R.D. Functional fear predicts public health compliance in the COVID-19 pandemic. Int. J. Ment. Health Addict. 2020, 1-14. [CrossRef]

27. Oosterhoff, B.; Palmer, C.A. Psychological correlates of news monitoring, social distancing, disinfecting, and hoarding behaviors among US adolescents during the COVID-19 pandemic. PsyArXiv 2020. [CrossRef] 
28. Krekel, C.; Swanke, S.; De Neve, J.-E.; Fancourt, D. Are Happier People More Compliant? Global Evidence from Three Large-Scale Surveys During COVID-19 Lockdowns; Social Science Research Network: Rochester, NY, USA, 2020.

29. Barceló, J.; Sheen, G.C.-H. Voluntary adoption of social welfare-enhancing behavior: Mask-wearing in Spain during the COVID-19 outbreak. PLoS ONE 2020, 15, e0242764. [CrossRef] [PubMed]

30. Chiorri, C.; Bracco, F.; Piccinno, T.; Modafferi, C.; Battini, V. Psychometric properties of a revised version of the ten item personality inventory. Eur. J. Psychol. Assess. 2014, 31, 109-119. [CrossRef]

31. Gosling, S.D.; Rentfrow, P.J.; Swann, W.B. A very brief measure of the big-five personality domains. J. Res. Personal. 2003, 37, 504-528. [CrossRef]

32. Jerusalem, M.; Schwarzer, R. Self-efficacy as a resource factor in stress appraisal processes. In Self-Efficacy: Thought Control of Action; Hemisphere Publishing Corp: Washington, DC, USA, 1992; ISBN 978-1-56032-269-6.

33. Sibilia, L.; Schwarzer, R.; Jerusalem, M. Italian Adaptation of the General Self Efficacy Scale: Self-Efficacy Generalized. Available online: http:/ / userpage.fu-berlin.de/ \{\}health/selfscal.htm (accessed on 14 May 2021).

34. Prati, G.; Pietrantoni, L.; Zani, B. A social-cognitive model of pandemic influenza H1N1 risk perception and recommended behaviors in Italy. Risk Anal. 2011, 31, 645-656. [CrossRef] [PubMed]

35. Wilson, R.S.; Zwickle, A.; Walpole, H. Developing a broadly applicable measure of risk perception. Risk Anal. 2019 , 39, 777-791. [CrossRef] [PubMed]

36. Ding, Y.; Du, X.; Li, Q.; Zhang, M.; Zhang, Q.; Tan, X.; Liu, Q. Risk perception of coronavirus disease 2019 (COVID-19) and its related factors among college students in China during quarantine. PLoS ONE 2020, 15, e0237626. [CrossRef] [PubMed]

37. Miller, W.R.; Johnson, W.R. A natural language screening measure for motivation to change. Addict. Behav. 2008, 33, 1177-1182. [CrossRef] [PubMed]

38. Capanna, C.; Stratta, P.; Collazzoni, A.; D’Ubaldo, V.; Pacifico, R.; Di Emidio, G.; Ragusa, M.; Rossi, A. Social connectedness as resource of resilience: Italian validation of the social connectedness scale-revised. J. Psychopathol. 2013, 19, 320-326.

39. Lee, R.M.; Robbins, S.B. Measuring belongingness: The social connectedness and the social assurance scales. J. Couns. Psychol. 1995, 42, 232-241. [CrossRef]

40. Gremigni, P.; Stewart-Brown, S. Una misura del benessere mentale: Validazione italiana della Warwick-Edinburgh mental well-being scale (WEMWBS). G. Ital. Psicol. 2011, 38, 485-508. [CrossRef]

41. Tennant, R.; Hiller, L.; Fishwick, R.; Platt, S.; Joseph, S.; Weich, S.; Parkinson, J.; Secker, J.; Stewart-Brown, S. The WarwickEdinburgh mental well-being scale (WEMWBS): Development and UK validation. Health Qual. Life Outcomes 2007, 5, 63. [CrossRef] [PubMed]

42. Di Fabio, A.; Gori, A. Measuring adolescent life satisfaction: Psychometric properties of the satisfaction with life scale in a sample of italian adolescents and young adults. J. Psychoeduc. Assess. 2016, 34, 501-506. [CrossRef]

43. Diener, E.; Emmons, R.A.; Larsen, R.J.; Griffin, S. The satisfaction with life scale. J. Pers. Assess. 1985, 49, 71-75. [CrossRef] [PubMed]

44. Watson, D.; Clark, L.A.; Tellegen, A. Development and validation of brief measures of positive and negative affect: The PANAS scales. J. Pers. Soc. Psychol. 1988, 54, 1063-1070. [CrossRef] [PubMed]

45. Terraciano, A.; McCrae, R.R.; Costa, P.T., Jr. Factorial and construct validity of the italian positive and negative affect schedule (PANAS). Eur. J. Psychol. Assess. 2003, 19, 131-141. [CrossRef] [PubMed]

46. Joinson, A.N. Self-disclosure in computer-mediated communication: The role of self-awareness and visual anonymity. Eur. J. Soc. Psychol. 2001, 31, 177-192. [CrossRef]

47. Joinson, A. Social desirability, anonymity, and internet-based questionnaires. Behav. Res. Methods Instrum. Comput. 1999, 31, 433-438. [CrossRef]

48. Schober, P.; Boer, C.; Schwarte, L.A. Correlation Coefficients: Appropriate Use and Interpretation. Anesth. Analg. 2018, 126, 1763-1768. [CrossRef]

49. Cohen, J. Statistical Power Analysis for the Behavioral Sciences; Routledge: London, UK, 2013; ISBN 978-0-203-77158-7.

50. ISTAT. Reazione dei Cittadini al Lockdown 5-21 Aprile 2020 Report No. 243357; Istituto Nazionale di Statistica: Rome, Italy, 2020; p. 11.

51. Bish, A.; Michie, S. Demographic and attitudinal determinants of protective behaviours during a pandemic: A review. Br. J. Health Psychol. 2010, 15, 797-824. [CrossRef] [PubMed]

52. Kroencke, L.; Geukes, K.; Utesch, T.; Kuper, N.; Back, M.D. Neuroticism and emotional risk during the COVID-19 pandemic. J. Res. Personal. 2020, 89, 104038. [CrossRef]

53. Tong, E.M.W. Personality influences in appraisal-emotion relationships: The role of neuroticism. J. Pers. 2010, $78,393-417$. [CrossRef] [PubMed]

54. Brailovskaia, J.; Margraf, J. Predicting adaptive and maladaptive responses to the coronavirus (COVID-19) outbreak: A prospective longitudinal study. Int. J. Clin. Health Psychol. 2020, 20, 183-191. [CrossRef]

55. Jose, R.; Holman, E.A.; Silver, R.C. The importance of the neighborhood in the 2014 ebola outbreak in the United States: Distress, worry, and functioning. Health Psychol. 2017, 36, 1181-1185. [CrossRef] [PubMed]

56. Mihashi, M.; Otsubo, Y.; Yinjuan, X.; Nagatomi, K.; Hoshiko, M.; Ishitake, T. predictive factors of psychological disorder development during recovery following SARS outbreak. Health Psychol. 2009, 28, 91-100. [CrossRef] [PubMed] 
57. Yip, P.S.F.; Cheung, Y.T.; Chau, P.H.; Law, Y.W. The impact of epidemic outbreak: The case of severe acute respiratory syndrome (SARS) and suicide among older adults in Hong Kong. Crisis, J. Crisis Interv. Suicide Prev. 2010, 31, 86-92. [CrossRef]

58. Li, J.-B.; Yang, A.; Dou, K.; Wang, L.-X.; Zhang, M.-C.; Lin, X.-Q. Chinese public's knowledge, perceived severity, and perceived controllability of COVID-19 and their associations with emotional and behavioural reactions, social participation, and precautionary behaviour: A national survey. BMC Public Health 2020, 20, 1589. [CrossRef] [PubMed]

59. Favieri, F.; Forte, G.; Tambelli, R.; Casagrande, M. The Italians in the time of coronavirus: Psychosocial aspects of the unexpected COVID-19 pandemic. Front. Psychiatry 2021, 12. [CrossRef]

60. Meo, S.A.; Abukhalaf, A.A.; Alomar, A.A.; Sattar, K.; Klonoff, D.C. COVID-19 pandemic: Impact of Quarantine on medical students' mental wellbeing and learning behaviors. Pak. J. Med. Sci. 2020, 36, S43-S48. [CrossRef] [PubMed]

61. Satici, B.; Saricali, M.; Satici, S.A.; Griffiths, M.D. Intolerance of uncertainty and mental wellbeing: Serial mediation by rumination and fear of COVID-19. Int. J. Ment. Health Addict. 2020, 1-12. [CrossRef]

62. Asnakew, Z.; Asrese, K.; Andualem, M. Community risk perception and compliance with preventive measures for COVID-19 pandemic in Ethiopia. Risk Manag. Healthc. Policy 2020, 13, 2887-2897. [CrossRef] [PubMed]

63. Almutairi, A.F.; BaniMustafa, A.; Alessa, Y.M.; Almutairi, S.B.; Almaleh, Y. Public trust and compliance with the precautionary measures against COVID-19 employed by authorities in Saudi Arabia. Risk Manag. Healthc. Policy 2020, 13, 753-760. [CrossRef]

64. Pan, Y.; Fang, Y.; Xin, M.; Dong, W.; Zhou, L.; Hou, Q.; Li, F.; Sun, G.; Zheng, Z.; Yuan, J.; et al. Self-reported compliance with personal preventive measures among chinese factory workers at the beginning of work resumption following the COVID-19 outbreak: Cross-sectional survey study. J. Med. Internet Res. 2020, 22, e22457. [CrossRef]

65. Rattay, P.; Michalski, N.; Domanska, O.M.; Kaltwasser, A.; Bock, F.D.; Wieler, L.H.; Jordan, S. Differences in risk perception, knowledge and protective behaviour regarding COVID-19 by education level among women and men in Germany. Results from the COVID-19 snapshot monitoring (COSMO) study. PLoS ONE 2021, 16, e0251694. [CrossRef]

66. Mevorach, T.; Cohen, J.; Apter, A. Keep calm and stay safe: The relationship between anxiety and other psychological factors, media exposure and compliance with COVID-19 regulations. Int. J. Environ. Res. Public. Health 2021, 18, 2852. [CrossRef] [PubMed] 